\title{
Ti and TiAl melting with a semi-industrial PAMCHR
}

\author{
Fabienne Ruby-Meyer ${ }^{\mathrm{a},}{ }^{*}$, Emiliane Doridot ${ }^{2}$, Jérôme Delfosse ${ }^{3}$, Stéphane Hans $^{2}$ \\ a. MetaFensch, Uckange, France \\ b. Aubert \& Duval, Les Ancizes, France \\ c. Safran Tech, Magny-les-Hameaux, France \\ * fabienne.ruby-meyer@metafensch.fr
}

\section{$\underline{\text { Abstract }}$}

Upscaling from laboratory trials to industrialization is a critical step in the development of new metallurgical processes and products. Pilot trials are an important way to provide data that can be used to better understand and model the industrial-scale process.

MetaFensch has invested in a semi-industrial Plasma Arc Melter Cold Hearth Refiner (PAMCHR) in order to support the development of the recycling of titanium scraps into aeronautical grade titanium alloy ingots.

This pilot supports the industrial scale PAMCHR of the company Ecotitanium in the frame of a collaborative project with Aubert \& Duval and Safran as industrial partners.

The work done on the pilot scale PAMCHR consists in studying the influence of various parameters like the type of melting feedstock, plasma arc parameters, operating pressure on the final quality of the cast ingot. The goal is to understand the physico-chemical mechanisms involved in the plasma arc interacting with the liquid metal in order to optimize the melting and refining parameters for the industrial scale furnace Ecotitanium (Ti64 alloy).

Ti64 and TiAl ingots were cast in $150 \mathrm{~mm}$ and $100 \mathrm{~mm}$ diameter. Chemical composition and solidification structure were characterized. The effect of the different process parameters on the titanium melt and on the ingot quality are studied. Examples of exploitation of the thermograms obtained with the thermal camera situated above the refining cold hearth will also be presented in this paper.

\section{Introduction}


MetaFensch is a French publicly funded R\&D platform created in 2014. Its goal is to help industrial actors bring their innovative metallurgical products or processes to market. Upscaling from laboratory trials to industrialization is a critical step in the development of new metallurgical processes and products. Pilot trials are an important way to provide data that can be used to better understand and model the industrial-scale process. At MetaFensch, research concerns following domains: melting, casting, powder metallurgy, metal recycling and process energy efficiency.

Metafensch has invested in a semi-industrial Plasma Arc Melter Cold Hearth Refiner (PAMCHR) Figure 1. This pilot supports the development of the recycling of titanium scraps into aeronautical grade titanium ingots.

A collaborative project is currently ongoing with Aubert \& Duval and Safran as industrial partners. The work done on the pilot scale PAMCHR consists in studying the influence of various parameters like the type of melting feedstock, plasma arc parameters and operating pressure on the final quality of the cast ingot. The goal is to understand the physico-chemical mechanisms involved in the plasma arc interacting with the liquid metal in order to optimize the melting and refining parameters for the industrial scale furnaces like the one built by Ecotitanium ${ }^{[1]}$.
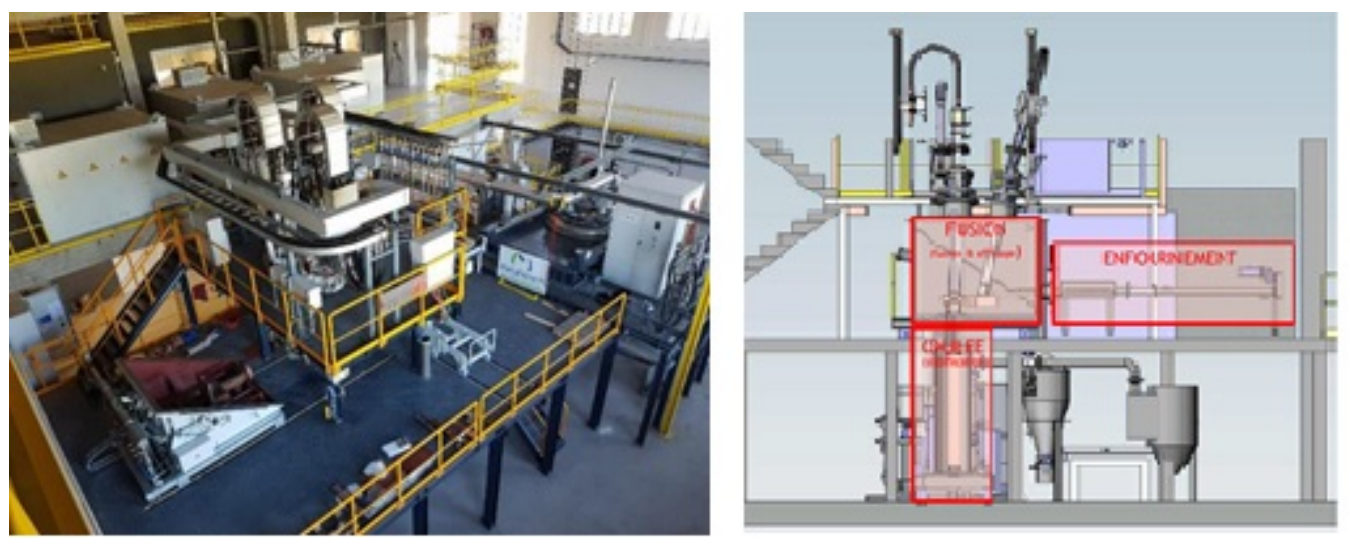

Figure 1: View of the PAMCHR pilot at MetaFensch.

\section{Material}

The pilot scale PAMCHR can be divided in three parts:

- A feeding area where different types of material can be loaded: bars, compacts of scraps, boxes containing different geometry of material (Figure 2). 


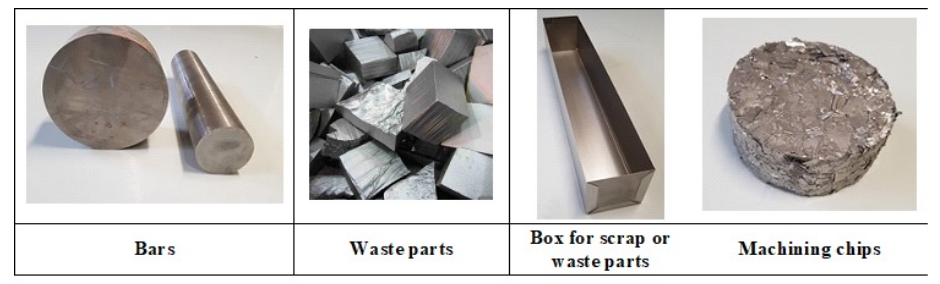

Figure 2: Types of melting feedstock.

- A melting area composed of two parts: the melting hearth crucible where the feedstock is melted, the refining hearth crucible dedicated to the purification of the metal (Figure 3). Cold crucible hearths are made of copper cooled by water, because of the high temperature reactivity of titanium, which cannot be melted in refractory materials. The titanium is melted and refined by plasma torches, in an inert gas environment. There are three plasma torches located over the melting hearth, the refining hearth and the ingot mold. In all experiments, plasma is $100 \%$ helium as well as the atmosphere in the furnace, but it is possible to work with a mixture of helium and argon.

- A casting area with the mold (Figure 3) and below the extraction chamber. Two diameters of ingots can be cast: 150 and $100 \mathrm{~mm}$ (Figure 4).

All around the furnace different sensors are installed for pressure, water temperature, gas flow control.

Four cameras are dedicated to the observation of the melting and process operating. A thermal camera is installed over the refining heart in order to follow the temperature at metal surface.

A gas atmosphere analyzer equipped with $\mathrm{H}_{2}, \mathrm{O}_{2}, \mathrm{~N}_{2}, \mathrm{H}_{2} \mathrm{O}$ and $\mathrm{Cl}_{2}$ detectors allows to control the composition of the furnace atmosphere.

All those data can be extracted after each trial. 

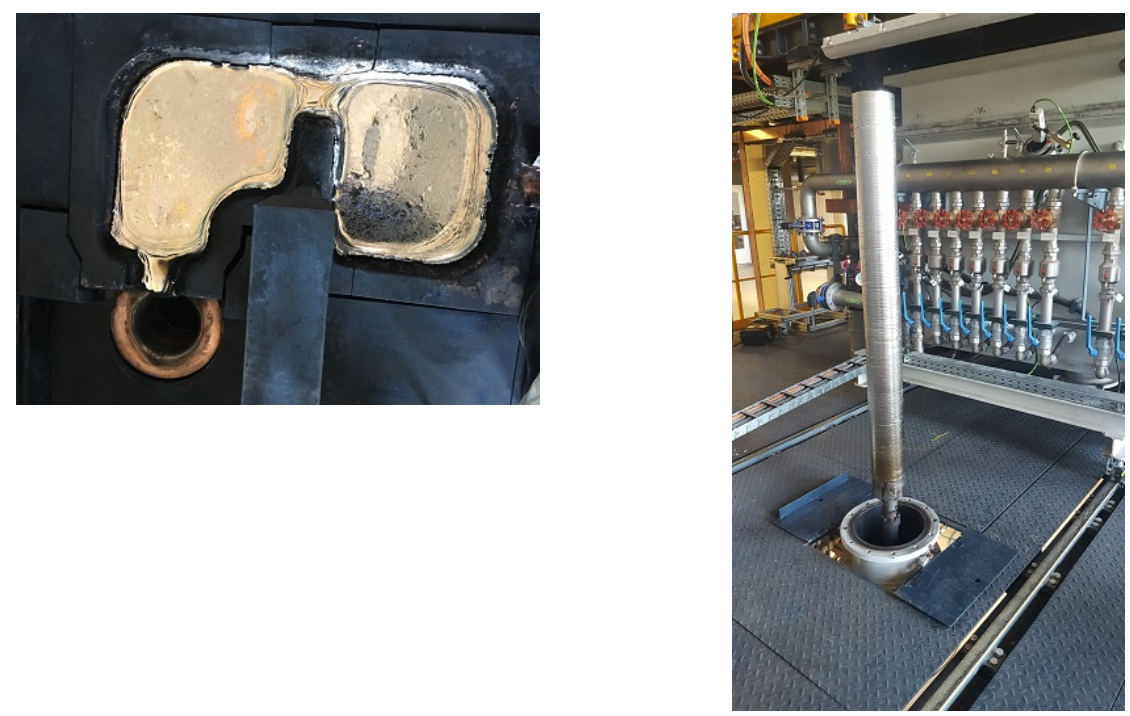

Figure 3: Melting and casting area.

Figure 4 : Example of ingot.

\section{$\underline{\text { 3. Solidification structure }}$}

The solidification structure of the cast ingot was controlled, both on Ti64 and TiAl ingots $150 \mathrm{~mm}$ diameter.

The ingots were cut in their length and the macrostructure revealed by acid etching (Figure 5).

In both alloys some cracks near the skin can be observed. The Ti64 ingot shows a basaltic structure on $2 / 3$ of the diameter and an equiaxed structure at the center. The TiAl ingot shows mainly a basaltic structure and a narrow equiaxed zone in the center. 


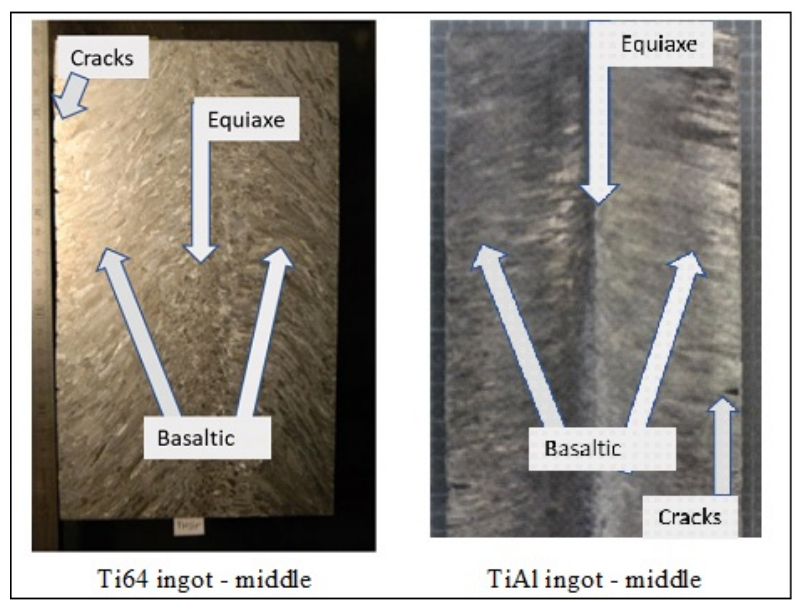

\section{Figure 5 : Macro-structure in remelted Ti64 ingot and TiAl ingot.}

\section{Results on remelted Ti64 alloy}

The first step of the RecyTiAl project consists in optimizing the melting and casting of Ti64 alloy. The torch patterns were those recommended by the PAMCHR supplier. The extraction speeds and parameters of torch 3 were optimized in order to obtain the best ingot surface. The internal quality was then examined by the partners.

The Ti64 ingots chemical composition and macrostructure were studied by Aubert\&Duval.

The chemical composition has been checked at top, middle and bottom of the ingots. For each position, an analysis was done near the skin, at mid radius and in the centre. The dispersion between skin, midradius and center is very low. It is represented as error bars in the graph of Figure 6 and Figure 7.

We can also notice that a homogeneous composition is obtained in the whole ingot. We observe also that for all alloying elements, the composition of the remelted ingot is the same as the composition of the introduced material except for hydrogen. In the case of hydrogen (Figure 8), the content in the feeding material was relatively high and dispersed (as it is shown by the vertical bars in the graph). But, in the ingot a homogeneous value was obtained. As it is described by Chinnis [2], the hydrogen decreases until reaching an equilibrium between the partial pressure of $\mathrm{H} 2$ in the gas phase and the $\mathrm{H}$ in the liquid titanium phase. 

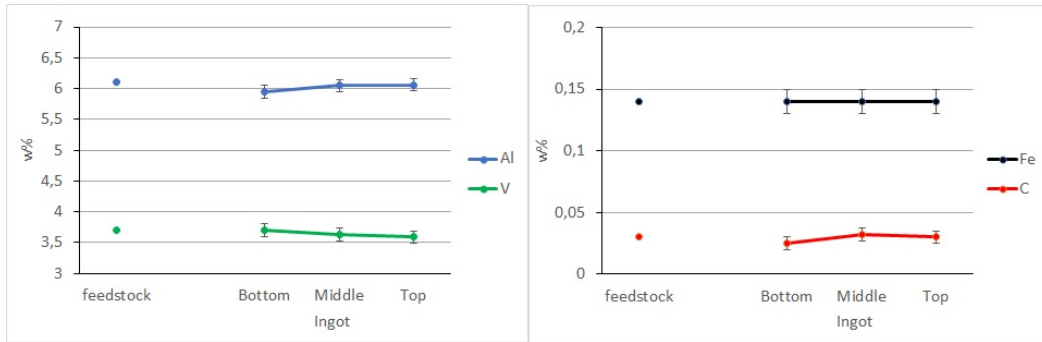

Figure 6: $\mathrm{Al}, \mathrm{V}, \mathrm{Fe}$ and $\mathrm{C}$ content in feeding material and in remelted ingot (Ti64 alloy).
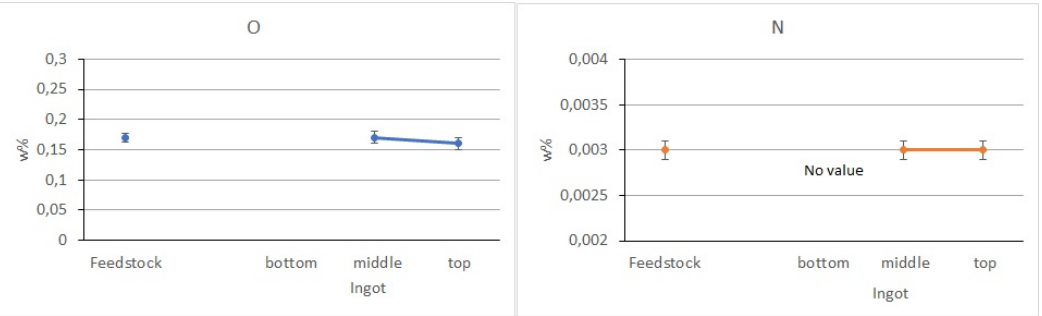

Figure 7: $\mathrm{O}$ and $\mathrm{N}$ content in feeding material and in remelted ingot (Ti64 alloy).

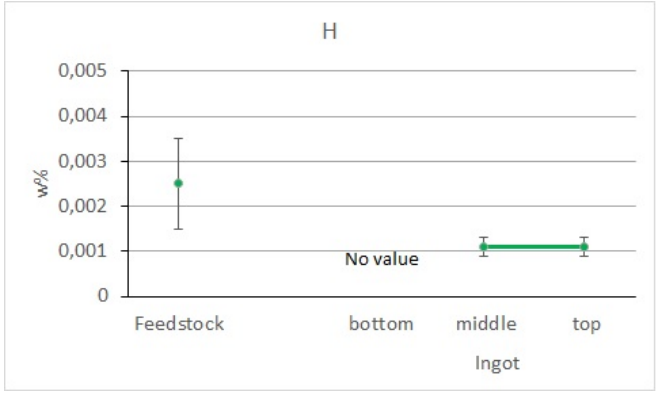

Figure $8: \mathrm{H}$ content in in feeding material and in remelted ingot (Ti64 alloy).

\section{Results on remelted TiAl alloy}

Remelting of TiAl alloy in the PAMCHR has also been tested. The first objective was to check if there is any aluminum evaporation during remelting [3]. Therefore, melting with two different working pressures were tested: 400 mbar and 900 mbar. The patterns as well as the torch parameters were those recommended by the PAMCHR supplier. 
The obtained ingots were characterised by SafranTech. The chemical composition has been checked at top, middle and bottom of the ingots. For each position, an analysis was done near the skin, at mid radius and in the centre. The dispersion between skin, mid-radius and center is very low. It is represented as error bars in the graph of Figure 9. It can be observed that at $400 \mathrm{mbar}$, the aluminium content on the ingot is slightly lower than at 900 mbar but the difference is smaller than $1 \%$ and the content stays inside the specification.

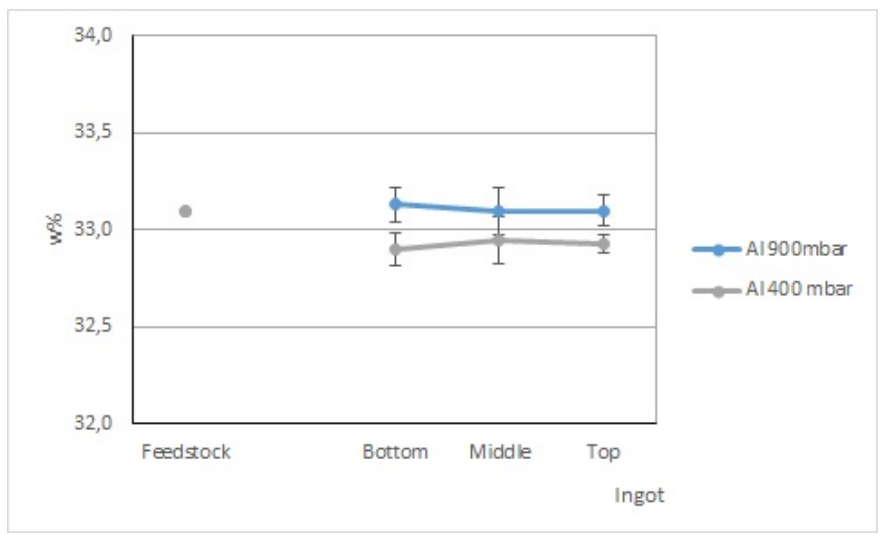

Figure 9 : Aluminium content at different positions of the TiAl ingots, one remelted at 900 mbar and one remelted 400 mbar.

\section{Effect of plasma parameters on LDI elimination}

The function of the refining hearth is to eliminate the LDI particles. The LDI inclusions like titanium nitrides can be eliminated by dissolution in the liquid titanium. The parameters which have an influence on the dissolution of these particles are the overheating of the liquid metal and the residence time.

The influence of the electric power on the overheat temperature of the metal in the refining crucible has been studied on the pilot PAMCHR. The results will be used for the validation of the model developed in the frame of a PhD at IJL-Nancy [4].

The parametric study is based on the exploitation of the thermograms recorded with the thermal camera located above the refining cold hearth (Figure 10). The emissivity of the liquid titanium has been set at 0.2 . It seems to be a good approximation because with this value the temperature near the cold wall of the crucible is nearly the liquidus of $\operatorname{Ti} 64\left(1650^{\circ} \mathrm{C}\right)$. 


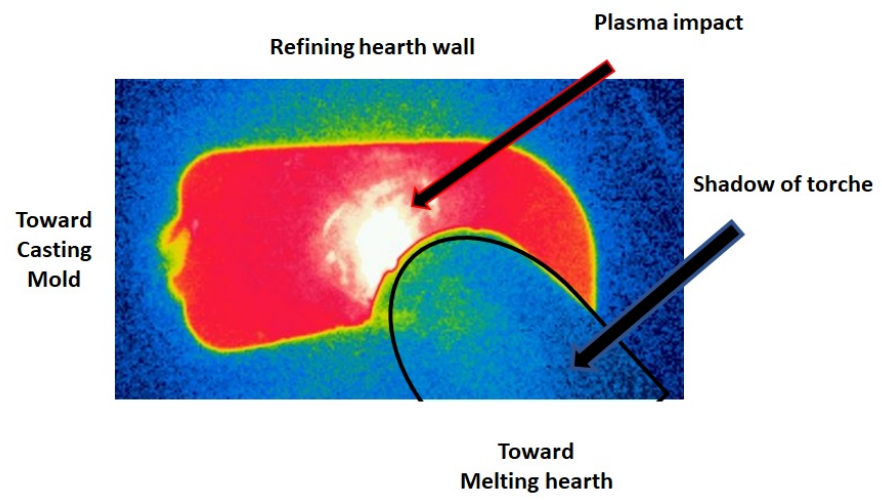

Figure 10 : Example of thermal cartography of liquid titanium in the refining hearth.

Additional tests were performed. The torch above the refining hearth was maintained at a fixed position and three different power values were tested: P1, P2 and P3. The thermograms were recorded by the thermal camera for about 10 minutes for each power value and the mean temperature at different points of the refining hearth surface calculated. In all cases the total surface of the refining hearth was liquid. An example of temperature at 3 positions in the cold hearth are given in Figure 11. Near the plasma the temperature is higher than $2000^{\circ} \mathrm{C}$ but it decreases rapidly when going from the torch toward the crucible walls.

Based on those thermograms, the overheat has been calculated at different points of the liquid surface for the three applied electric powers. Results are presented in Figure 12. Near the impact of the plasma arc, the overheat is directly influenced by the power value but then the difference of overheat decreases rapidly when moving toward the pouring lip or the middle of the crucible.
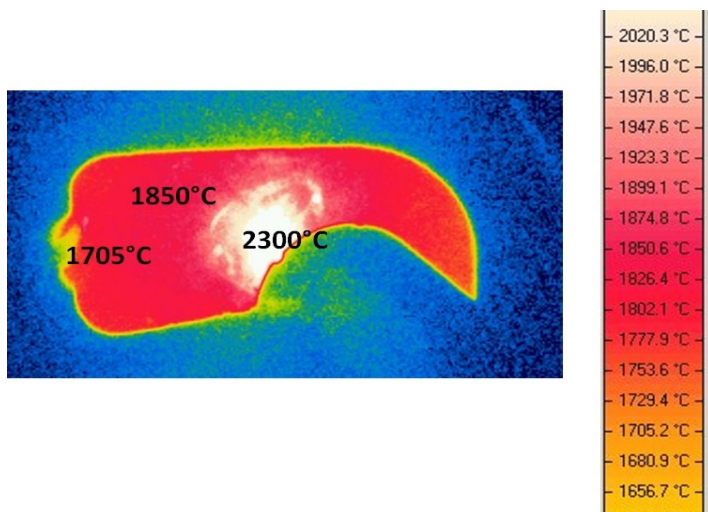
Figure 11 : Example of temperature measured near the torch, in the middle of the refining hearth and near the pouring lip.

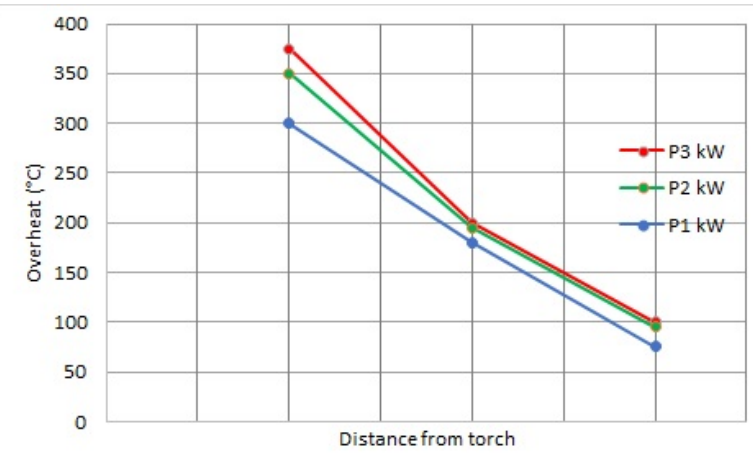

\section{Figure 12 : Overheat at different distances from the torch impact.}

This first set of tests will be reproduced once more time in order to evaluate the precision of the temperature measurement by thermal camera. For example, the error due to the applied emissivity must be evaluated especially near the torch where the emissivity of the liquid titanium is affected by the plasma.

The same type of methodology will be applied to TiAl in order to optimise the remelting parameters of this alloy.

Experiments to define the residence time of a particle in the refining hearth are ongoing (with copper as tracing element). The results of the experiments carried out in the pilot furnace are used for the validation of the model currently developed in the frame of a $\mathrm{PhD}$ at IJL [4].

\section{Conclusion}

The PAMCHR from Metafensch is a pilot furnace which contributes, in the framework of RecyTiAL project, to find the most optimised condition to produce Ti64 alloy ingots, at industrial scale, in Ecotitanium. It is also used to define the most optimised production parameters of TiAl alloys.

Until now, following results are obtained on the pilot PAMCHR of MetaFensch: 
- the chemical composition of the cast ingot is very close to the one of the feeding materiel. Even for TiAl, there is quite no evaporation of the aluminium at low working pressure. The ingots composition is homogeneous in the length and the section of the ingots. No segregation is observed. The expected macro-structure is obtained. Some porosities are present at ingot surface, but the skin aspect will be improved by testing other casting parameters.

- $\quad$ A methodology for estimating the overheat of the liquid titanium in the cold hearth crucible has been developed by using the thermal camera. Further tests will be done with that method. A methodology for the estimation of the residence time in the cold hearth crucibles has also been developed. The trials are ongoing. The results of those tests are destinated to the validation of the PAMCHR model developed in the frame of a PhD at IJL in Nancy.

\section{Acknowledgment}

MetaFensch acknowledges the support of the French "Investissements d'Avenir" program, the French environmental agency (ADEME) and the European FEDER program.

\section{References}

[1] E. Doridot et al, Proceedings Titanium'19 (2019)

[2] W.R. Chinnis, W.H. Buttrill "Production Titanium in plasma cold hearth melting", Proceedings of Titanium'92 (1992).

[3] J.P. Bellot, E. Hess, D. Ablitzer "Aluminium volatilization and inclusion removal in the elctron beam cold hearth melting og Ti alloys", Metallurgical and Matarials Transaction B, Vol. 31B (2000), 845-854

[4] L. Decultot, A. Jardy, S. Hans, E. Doridot, J. Delfosse, F. Ruby-Meyer, J.P. Bellot "Characterization of the thermal flux transferred by the plasma arc to the surfade of the bath in the plasma arc melting cold heart refining process" Proceedings Titanium'19 (2019) 